\title{
An Experimental Demonstration of a Multi-element Flame Photometer: Determination of Salt Concentration in Soy Sauce
}

\author{
Hiu Tung $\mathrm{Chu}^{1}$, Spencer E. Taylor ${ }^{1}$ \\ ${ }^{1}$ Centre for Petroleum and Surface Chemistry, Department of Chemistry, University of Surrey, Guildford, Surrey GU2 \\ $7 \mathrm{XH}, \mathrm{UK}$ \\ Correspondence: Spencer E. Taylor, Centre for Petroleum and Surface Chemistry, Department of Chemistry, University \\ of Surrey, Guildford, Surrey GU2 7XH, UK. Tel: +44 1483 681999. E-mail: s.taylor@surrey.ac.uk.
}

$\begin{aligned} & \text { Received: November 4, } 2015 \\ & \text { Accepted: November 19, } 2015 \quad \text { Online Published: December 10, } 2015 \\ & \text { doi:10.5539/ijc.v8n1p25 }\end{aligned}$ URL: http://dx.doi.org/10.5539/ijc.v8n1p25

\begin{abstract}
The routine determination of some group 1 and group 2 metals is important because of their biological, physiological and industrial relevance. Flame atomic emission spectrometry, or flame photometry (FP), is well-suited to the determination of several alkali and alkaline earth metals which are easily ionized in a gas flame. Here, we consider the application of flame photometry as a simple but sensitive analytical method which is normally restricted to the determination of one element at a time. We have demonstrated the use of a new multi-element instrument for the simultaneous determination of four cations, namely $\mathrm{Li}^{+}, \mathrm{Na}^{+}, \mathrm{K}^{+}$and $\mathrm{Ca}^{2+}$ in six different brands of soy sauce currently available in the UK. The $\mathrm{Na}^{+}$concentrations are compared with quoted nutrition values given on the product labels, and found to be in very good agreement for "low-salt" soy sauce, but some departures were noted in the higher salt products, the present results indicating higher salt content than the supplied data. $\mathrm{Li}^{+}$concentrations were below the detection limit (i.e., $<1 \mathrm{mg} / \mathrm{L}$ under the conditions used in this study). This demonstration study has shown multi-element flame photometry to be a straightforward means of analysing water-based products that could be more widely adopted for many different applications. Typical maximum concentrations for the direct analysis of aqueous solutions were found to be $50 \mathrm{mg} / \mathrm{L}\left(\mathrm{Li}^{+}\right), 200 \mathrm{mg} / \mathrm{L}\left(\mathrm{Na}^{+}, \mathrm{K}^{+}\right)$and $1000 \mathrm{mg} / \mathrm{L}\left(\mathrm{Ca}^{2+}\right.$. Although not the primary goal of this study, we noted some variance between the present results and values quoted on some of the products. This may relate to the use of indirect methods for estimating salt (sodium) concentrations. The use of flame photometry, however, would provide a rapid measurement of important cations in a wide range of applications.
\end{abstract}

Keywords: cation analysis, flame photometry, soy sauce

\section{Introduction}

Quantification of the most common group 1 and group 2 metal ions in solution is relevant to many technological and medical areas. The alkali and alkaline earth metal ions, such as lithium, sodium, potassium, magnesium and calcium are important biologically and physiologically, as well as being relevant to many industrial processes. Thus, the routine, accurate and reliable quantification of sodium, potassium and calcium is particularly important in a wide range of applications.

Flame atomic absorption spectroscopy (FAAS) is one of the most commonly-used analytical techniques in laboratories for the determination of individual elements. FAAS superseded flame photometry (FP, or flame atomic emission spectrometry) for the accurate determination of a wide range of elements. However, FP remains a simpler, cost-effective and robust technique which is ideally-suited to the quantitative determination of the most easily ionizable metals which are detectable through their characteristic emission spectra.

The first flame photometers were developed and became available commercially in the 1940s (Barnes et al., 1945). Until recently, however, both FP and FAAS were restricted to the measurement of a single element at a time. However, one of the aims of the present study is to demonstrate a flame photometer capable of the simultaneous determination of five elements, namely $\mathrm{Li}, \mathrm{Na}, \mathrm{K}, \mathrm{Ca}$ and $\mathrm{Ba}$. In this paper we describe the use of a new instrument and illustrate its application to the quantification of four of the above elements in commercial soy sauce samples. In the case of sodium, this allows the results for each product to be compared to the nutritional information supplied by the manufacturer on the product packaging.

The use of flame photometry for the determination of salinity in various foods has attracted further interest in the past 
few years owing to the importance given to the control of dietary salt intake, and the consequential need for improved information. Thus, for example, Chen et al. conducted a thorough study into the sodium content of various processed foods using flame photometry and found the results to be in excellent agreement with corresponding results using Mohr's titration method (Chen et al., 2005), although the former was a much simpler technique which is susceptible to fewer experimental difficulties. Moreover, these workers investigated potential interference on the sodium measurements from added potassium (up to $1 \mathrm{ppm}$ ) and calcium (up to $100 \mathrm{ppm}$ ). In these cases, whilst $1 \mathrm{ppm} \mathrm{K}^{+}$ increased the apparent $\mathrm{Na}^{+}$result, $100 \mathrm{ppm} \mathrm{Ca}{ }^{2+}$ showed no effect. FP approaches to the quantification of sodium concentrations in consumer products such as sports drinks and coconut water have also recently been demonstrated (LaFratta et al., 2013; Moraes et al., 2014).

Other applications of FP centre particularly on environmental monitoring, as would be expected, and also in forensic analysis of human blood serum to, for example, identify a link between sodium and potassium concentrations and time since death (Singh et al., 2002). Surprisingly, there is scant literature relating to the use of FP in manufacturing. In one example, in order to avoid cracking of concrete, undesirable alkali-silica reactions during cement manufacture have to be avoided through careful monitoring of sodium and potassium concentrations, prompting the development and application of a flow injection FP technique, permitting quality control of the product (Junsomboon and Jakmunee, 2011). Flow injection had been used previously for the FP analysis of $\mathrm{Na}^{+}$and $\mathrm{K}^{+}$in beer, since various metal ions impact on flavour and stability and their control is therefore of particular importance (Fernandes et al., 1997).

\subsection{Description of the BWB XP Flame Photometer (BWB Technologies, 2012)}

Figure 1 shows features of the BWB XP instrument which it shares with other flame photometers. The ability to determine the different emission wavelengths simultaneously lies in the unique filter/photo-detector layout.

The nebuliser atomizes the solutions and the resultant aerosols are pumped into the mixing chamber where they are mixed in constant proportion with the flammable gas, most commonly propane. The gas carries the aerosol droplets to the burner, and upon ignition at the burner tip, the aerosol is vaporised, the metal ions are reduced and thermally dissociate into atoms in their excited state. Radiation containing characteristic wavelengths is emitted as the excited-state atoms return to their ground states.

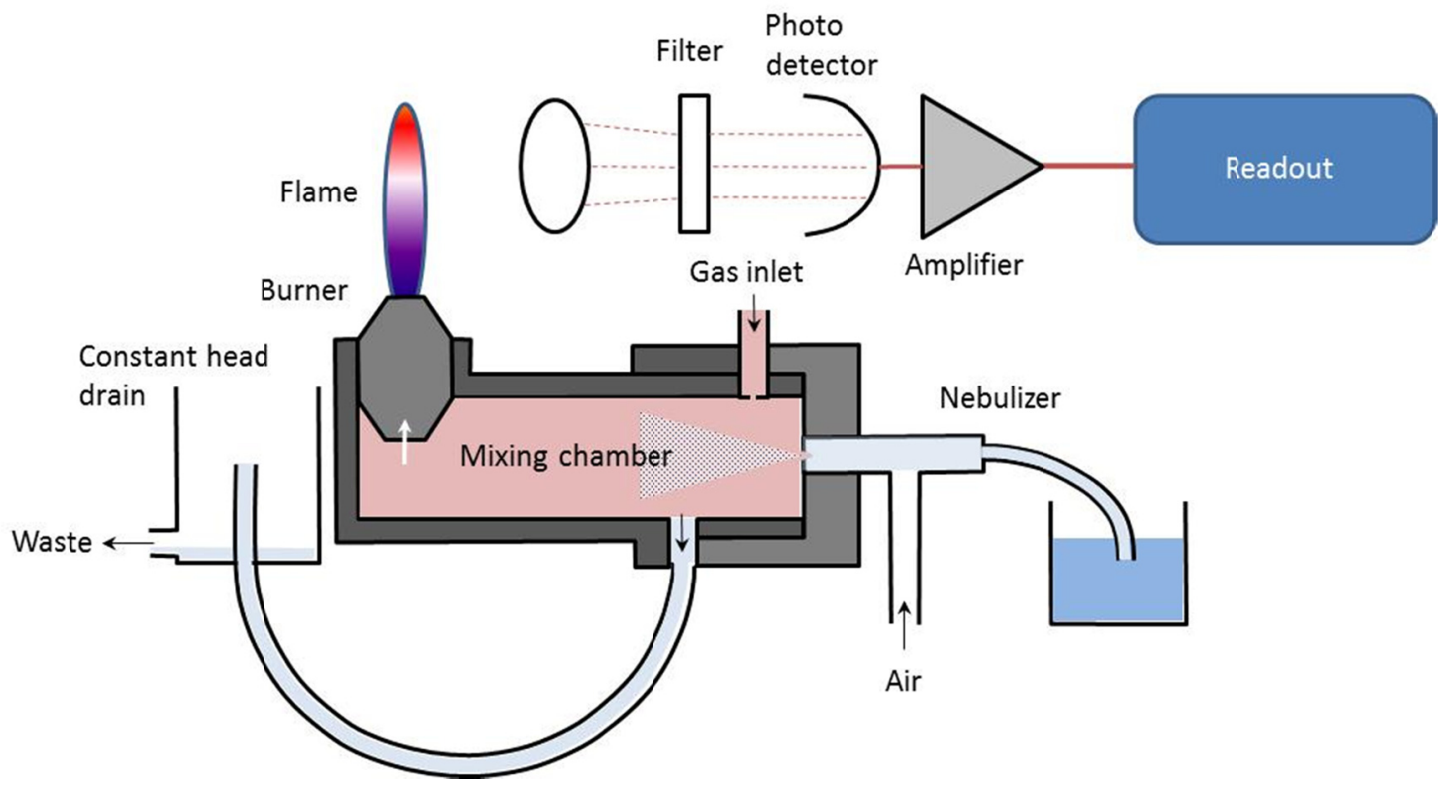

Figure 1. The basic layout of a flame photometer (adapted from BWB Technologies, 2012).

The emitted wavelengths produced by alkali and alkaline earth metals lie within the visible region of the electromagnetic spectrum, and the intensities of the respective wavelength regions associated with specific elements are isolated by different filters. In common with traditional FP measurements, the intensity of emitted light at the characteristic wavelength of each atom is directly proportional to its concentration. The instrument allows for multi-element calibration using suitable traceable standard solutions.

\subsection{Salt Concentration in Soy Sauce}

Public awareness of the sodium content of many processed food products has increased owing to health issues resulting from the over-consumption of salt. Soy sauce is one of the most common and popular cooking ingredients used 
worldwide. There are more than fifty brands of light and dark soy sauces available in the UK market, for example. Each type has a different salinity which is related to their origin and method of production. The aim of the present study is to demonstrate the calibration and use of the BWB XP flame photometer as applied to the determination of $\mathrm{Li}^{+}, \mathrm{Na}^{+}, \mathrm{K}^{+}$ and $\mathrm{Ca}^{2+}$ concentrations in different examples of soy sauce; here, we analyse six locally purchased products. Other than sodium (chloride), the quantification of other specific metal cations has hitherto been unreported to the present authors' knowledge, and as such this not only represents an examination of the use of flame photometry, it is also relevant to food quality monitoring.

"Salt" content in such products is commonly calculated based on Mohr's titration method for chloride ion using silver nitrate solution, or from conductivity measurements. However, as indicated by other authors (Chen et al., 2005; Vieira et al., 2012), such indirect methods do not provide unequivocal determinations of sodium, and, importantly, may be unlikely to account for any other sources of sodium that may be present.

\section{Experimental}

\subsection{Materials}

Fluka ${ }^{\circledR}$ Multi Cation Standard 1 for Ion Chromatography was obtained from Sigma-Aldrich UK Ltd. Cation concentrations contained in this traceable standard are $200 \mathrm{mg} / \mathrm{L} \mathrm{Na}^{+}, \mathrm{K}^{+}$and $\mathrm{Mg}^{2+}, 50 \mathrm{mg} / \mathrm{L} \mathrm{Li}^{+}, 400 \mathrm{mg} / \mathrm{L} \mathrm{NH}_{4}^{+}$, and $1000 \mathrm{mg} / \mathrm{L} \mathrm{Ca}^{2+}$. Water was deionized (resistivity $=18.2 \mathrm{MS} / \mathrm{m}$ ) from a Millipore Direct-Q system. Details of the soy sauce samples purchased locally from UK supermarkets are given in Table 1.

Table 1. Type and origin of the soy sauce samples.

\begin{tabular}{lll}
\hline Soy sauce sample & Type & Origin \\
\hline A & Light & China \\
B & Dark & China \\
C & Light & Korea \\
D & Light & Malaysia \\
E & Light & Hong Kong \\
F & Light & The Netherlands \\
\hline
\end{tabular}

\subsection{Methods}

As mentioned above, the BWB XP flame photometer (BWB Technologies, Newbury, Berks., UK) was used in this study. Propane gas was the fuel supply and the flame was set to the manufacturer's recommended height of $\sim 10 \mathrm{~mm}$. The photometer was allowed to reach its working conditions for 45 minutes with continuous deionized water aspiration before calibrating.

Calibration of the flame photometer according to the manufacturer's instructions was carried out immediately before making sample measurements. Solutions of known concentrations of $\mathrm{Li}^{+}, \mathrm{Na}^{+}, \mathrm{K}^{+}$and $\mathrm{Ca}^{2+}$ (as chloride salts) were prepared by diluting the Multi Cation Standard (which contains: $50 \mathrm{mg} / \mathrm{L} \mathrm{Li}^{+}, 200 \mathrm{mg} / \mathrm{L} \mathrm{Na}^{+}, 200 \mathrm{mg} / \mathrm{L} \mathrm{K}^{+}$and 1000 $\mathrm{mg} / \mathrm{L} \mathrm{Ca}^{2+}$ ) with deionized water, avoiding contact with glass apparatus (Table 2). Duplicate measurements were made on each solution, and a background (deionized water) reading was also taken for each element.

Table 2. Cation concentrations made by dilution of the traceable standard used for the calibrations.

\begin{tabular}{ccccc}
\hline Calibration & \multicolumn{4}{c}{ Cation concentration $(\mathrm{mg} / \mathrm{L})^{*}$} \\
\cline { 2 - 5 } solution & $\mathrm{Li}^{+}$ & $\mathrm{Na}^{+}$ & $\mathrm{K}^{+}$ & $\mathrm{Ca}^{2+}$ \\
\hline 1 & 1.25 & 5 & 5 & 25 \\
2 & 2.5 & 10 & 10 & 50 \\
3 & 12.5 & 50 & 50 & 250 \\
4 & 25 & 100 & 100 & 500 \\
5 & 50 & 200 & 200 & 1000 \\
\hline
\end{tabular}

*Prepared by dilution of the traceable standard solution.

The six commercial products (Table 1) were diluted with deionized water by a (volume) factor of 1000 (using calibrated Gilson pipettes and class A polypropylene volumetric flasks), and analyzed using the BWB XP instrument in multi-ion mode to determine the four cations indicated above $\left(\mathrm{Ba}^{2+}\right.$ was not analyzed during the course of this work).

Errors in the analyses arose mainly from each of the dilutions, and are estimated as $0.1 \%$. However, the quoted errors obtained by averaging replicate analyses are larger.

\section{Results and Discussion}

\subsection{Instrument Calibration}

Each of the calibration plots relating the response of the flame photometer to cation concentration showed excellent linear relationships, with determination coefficients $\geq 0.994$. The linear regression equations that were subsequently used 
to calculate cation concentrations in the soy sauce samples are summarized in Table 3 for the four cations studied.

Table 3. A summary of the linear regression data for the cation determinations, according to the equation: photometer reading $=A\left[\mathrm{M}^{n+}\right]$, where the cation concentrations are in $\mathrm{mg} / \mathrm{L}$.

\begin{tabular}{cccc}
\hline Cation & $A(\mathrm{~L} / \mathrm{mg})$ & $\begin{array}{c}\text { Determination coefficient, } \\
\mathrm{R}^{2}\end{array}$ & $\begin{array}{c}\text { Concentration range } \\
(\mathrm{mg} / \mathrm{L}) \text { used for } \\
\text { calibration }\end{array}$ \\
\hline $\mathrm{Li}^{+}$ & 260.25 & 0.9999 & $0-50$ \\
$\mathrm{Na}^{+}$ & 282.73 & 0.9946 & $0-200$ \\
$\mathrm{~K}^{+}$ & 361.84 & 0.9991 & $0-200$ \\
$\mathrm{Ca}^{2+}$ & 12.563 & 0.9957 & $0-1000$ \\
\hline
\end{tabular}

\subsection{Cation Concentrations in the Soy Sauce Samples}

Analysis of each diluted soy sauce sample was carried out exactly as for the calibration solutions. Duplicate measurements were made on each sample and the results were averaged. In our analyses, lithium concentrations were found to be below the detection limit $(\sim 0.1 \mathrm{mg} / \mathrm{L}$ for all cations, estimated from the calibration data and baseline results for deionized water), but as suggested by a reviewer, it would be appropriate to try to identify this cation using lower dilution factors. However, for the present, only concentration data for the remaining three elements are presented for the various samples.

Thus, sodium, potassium and calcium are shown in Figure 2. These are seen to vary from sample to sample, although the cation concentrations are generally in the same respective ranges. Some specific differences are apparent however, as samples B and D are comparatively low in potassium, whilst samples A and D are higher in calcium.

The sodium concentrations are seen to fall into two categories (Figure 2a) which we term "high-salt" (samples A, B and C) and "low-salt" (samples D, E and F), which approximate to $>50,000$ and $<50,000 \mathrm{mg} / \mathrm{L}$ salt, respectively. Product E is specifically retailed as being "reduced-salt".

On the other hand, the potassium concentrations are more variable and are seen not to follow the sodium concentrations in any systematic way. The calcium concentrations are intermediate between the sodium and potassium values and, if anything, are relatively similar from sample to sample.

Table 4 summarizes the sodium concentration data obtained for the six soy sauce samples, and compares these with manufacturers' nutrition labels given on the product packaging. Also shown are the ratios between the experimental sodium concentrations and those quoted by the manufacturers. The latter are also seen to fall into the same two categories indicated above - the "high-salt" products A, B and C for which the measured values exceed the manufacturers' figures by a factor between 1.3 and 2.1, and the "low-salt" products D, E and F for which the experimental values are in excellent agreement with the manufacturers' data.

Table 4. Sodium concentrations calculated from the manufacturers' nutrition labels together with flame photometry results.

\begin{tabular}{cccc}
\hline $\begin{array}{c}\text { Soy sauce } \\
\text { sample }\end{array}$ & $\begin{array}{c}\text { Sodium concentration from } \\
\text { the label } \\
(\mathbf{m g} / \mathbf{L}) *\end{array}$ & $\begin{array}{c}\text { Sodium concentration from } \\
\text { flame photometry (mg/L) }\end{array}$ & $\begin{array}{c}\text { Ratio of flame photometry } \\
\text { sodium concentration to } \\
\text { manufacturers' value* }\end{array}$ \\
\hline A & 67693 & 98670 & 1.45 \\
B & 40537 & 86730 & 2.14 \\
C & 63000 & 81230 & 1.29 \\
D & 45900 & 45198 & 0.98 \\
E & 44500 & 42535 & 0.96 \\
F & 45600 & 45817 & 1.00 \\
\hline
\end{tabular}

\footnotetext{
* Converted from the manufacturers' quoted salt (sodium chloride) values.
} 


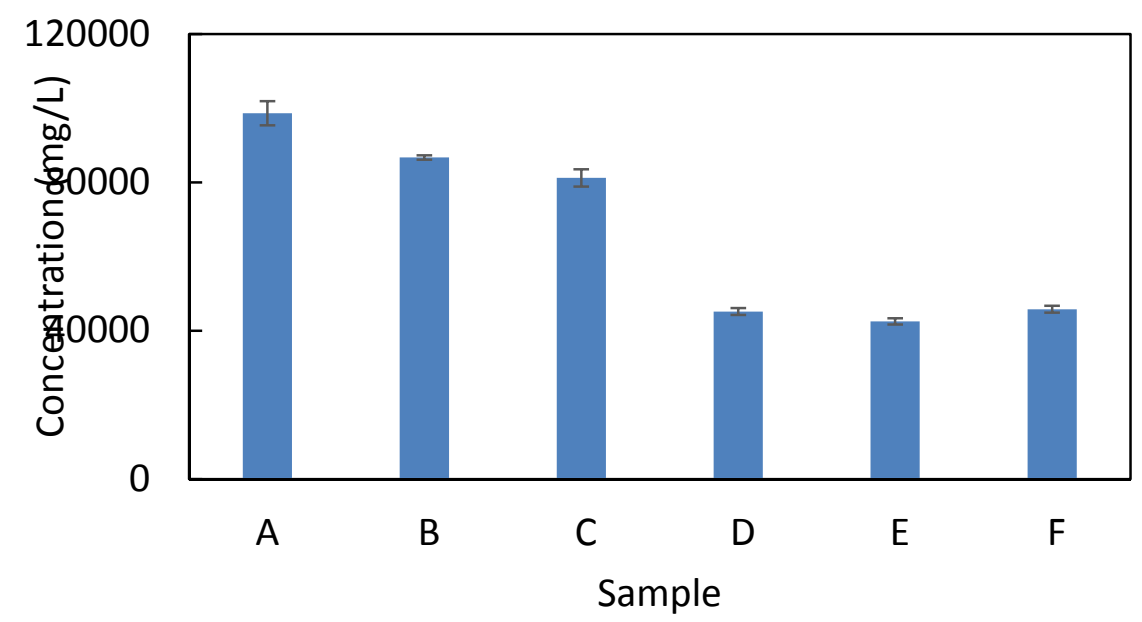

(a)

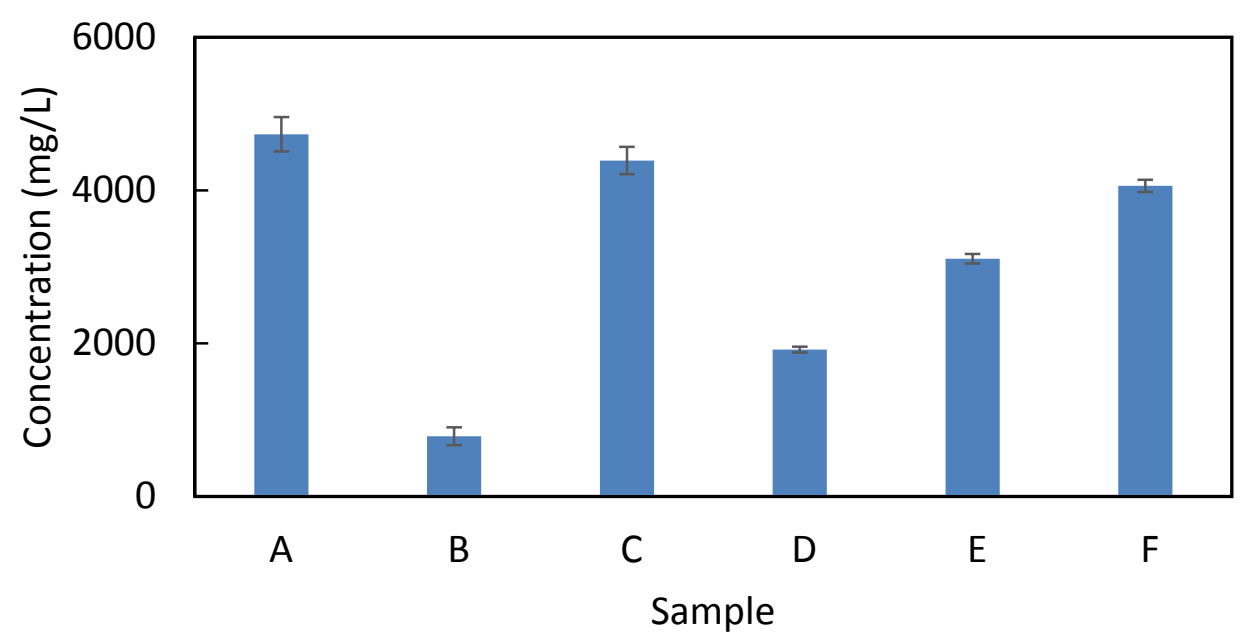

(b)

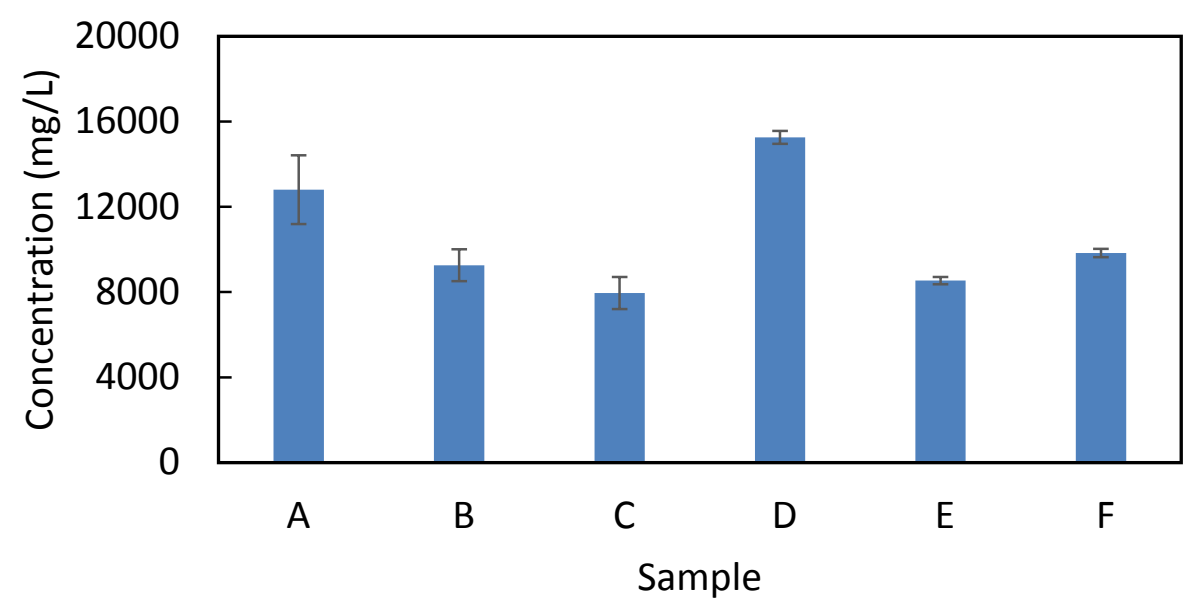

Figure 2. Comparison of the actual cation concentrations in the soy sauce samples: (a) $\mathrm{Na}^{+}$, (b) $\mathrm{K}^{+}$, (c) $\mathrm{Ca}^{2+}$.

Since all the soy sauce brands studied are supplied in glass bottles, it is possible that a small increase could have originated through dealkalization of glass. However, apart from this being expected to apply to all the samples, it is clearly not evident from the data. More likely, it would be expected that sodium is present in the products in forms other than sodium chloride.

Various studies have considered methods for reducing the sodium concentration of soy sauce. Desalination by 
nanofiltration (Luo et al., 2009; 2012) and electrodialysis (Fidaleo et al., 2012; 2013) are two examples in which salt concentrations (and sodium concentrations by inference) have been determined by indirect means, and which could benefit from the direct analysis as described in the present work. Likewise, in other industries where desalting is also an important consideration, for example in the refining of crude oil, flame photometry could also be used to provide process efficiency information.

\section{Conclusions and Implications}

Flame photometry is a relatively old analytical technique, but with modern developments it provides a simple but robust method to determine alkali and alkaline earth metal cations in a variety of situations, from laboratory to field. In addition, the ability to determine these metal ions in a variety of familiar products can also be applied in many different teaching and learning situations (see also LaFratta et al., 2013; Moraes et al., 2014), exemplifying the value of such analytical methods in fields as diverse as mining and medicine.

Thus, the present demonstration study has shown multi-element flame photometry to be a straightforward means of analysing water-based products that could be more widely adopted for many different applications. Concentrations as low as $1 \mathrm{mg} / \mathrm{L}(\mathrm{ppm})$ and possibly lower, and as high as $50 \mathrm{mg} / \mathrm{L}\left(\mathrm{Li}^{+}\right), 200 \mathrm{mg} / \mathrm{L}\left(\mathrm{Na}^{+}, \mathrm{K}^{+}\right)$and $1000 \mathrm{mg} / \mathrm{L}\left(\mathrm{Ca}^{2+}\right)$ can routinely be achieved using the BWB instrument, which is a range that is satisfactory for many applications.

Although it was not the primary goal of this study, we have noted some disagreement between our results and the $\mathrm{Na}^{+}$ (or $\mathrm{NaCl}$ ) concentrations accompanying the different products. Since the US Food and Drug Administration's recommended intake of sodium is no more than $2400 \mathrm{mg}$ per day, the results indicate that consuming $25 \mathrm{~mL}$ of the product with the highest sodium level will exceed this recommendation (Food and Drug Administration, 2012). Studies continue to address dietary salt intake (Brown, 2009) and the salt content of various foods (e.g., Jaworowska et al., 2012), and generally show higher-than-recommended levels in particular population groups (Tian et al., 1996; Yu et al., 2014), although some possible beneficial consequences should never be ruled out (Kurosawa et al. 2006), which indicates the need for further careful epidemiological and analytical research into this topic.

\section{Acknowledgements}

We are grateful to BWB Ltd personnel for supplying the XP flame photometer and providing training on its use, and to BP for financial support to the Centre for Petroleum and Surface Chemistry at the University of Surrey.

\section{References}

Barnes, R. B., Richardson, D., Berry, J. W., \& Hood, R. L. (1945). Flame Photometry. A Rapid Analytical Procedure. Ind. Eng. Chem. Anal. Ed., 17, 605-611. http://dx.doi.org/10.1021/i560146a001

Brown, I. J., Tzoulaki, I., Candeias, V., \& Elliott, P. (2009). Salt Intakes Around the World-Implications for Public Health. Int. J. Epidemiology, 38, 791-813. http://dx.doi.org/10.1093/ije/dyp139

BWB Technologies UK Ltd. (2012). A Guide to Flame Photometer Analysis.

Chen, M. J., Hsieh, Y. T., Weng, Y. M., \& Chiou, R. Y. Y. (2005). Flame Photometric Determination of Salinity in Processed Foods. Food Chem., 91, 765-770. http://dx.doi.org/10.1016/j.foodchem.2004.10.002

Fernandes, S. M. V., Rangel, A. O. S. S., \& Lima, J. L. F. C. (1997). Flow Injection Determination of Sodium, Potassium, Calcium, and Magnesium in Beer by Flame Emission and Atomic Absorption Spectrometry. J. Agric. Food Chem., 45, 1269-1272. http://dx.doi.org/10.1021/jf9604347

Fidaleo, M., Moresi, M., Cammaroto, A., Ladrange, N., \& Nardi, R. (2012). Soy Sauce Desalting by Electrodialysis. $J$. Food Eng., 110, 175-181. http://dx.doi.org/10.1016/j.jfoodeng.2011.06.002

Fidaleo, M., Moresi, M., Cammaroto, A., Ladrange, N., \& Nardi, R. (2013). Modelling of Soy Sauce Desalting by Electrodialysis. Food Bioprocess Technol., 6, 1681-1695. http://dx.doi.org/10.1007/s11947-012-0807-8

Food and Drug Administration (2012). Sodium-Look at the Label, Sodium Fact Sheet. http://www.fda.gov/downloads/Food/IngredientsPackagingLabeling/UCM315630.pdf last accessed 2 July 2015.

Jaworowska, A., Blackham, T., Stevenson, L., \& Davies, I. G. (2012). Determination of Salt Content in Hot Takeaway Meals in the United Kingdom. Appetite, 59, 517-522. http://dx.doi.org/10.1016/j.appet.2012.06.018

Junsomboon, J., \& Jakmunee, J. (2011). Determination of Potassium, Sodium, and Total Alkalies in Portland Cement, Fly Ash, Admixtures, and Water of Concrete by a Simple Flow Injection Flame Photometric System. J. Automat. Methods Man. Chem., 742656. http://dx.doi.org/10.1155/2011/742656

Kurosawa, M., Kikuchi, S., Xu, J., \& Inaba, Y. (2006). Highly Salted Food and Mountain Herbs Elevate the Risk for Stomach Cancer Death in a Rural Area of Japan. J. Gastroent. Hepat., 21, 1681-1686. 
http://dx.doi.org/10.1111/j.1440-1746.2006.04290.x

LaFratta, C. N., Jain, S., Pelse, I., Simoska, O., \& Elvy, K. (2013). Using a Homemade Flame Photometer to Measure Sodium Concentration in a Sports Drink. J. Chem. Educ., 90, 372-375. http://dx.doi.org/10.1021/ed3004758

Luo, J., Ding, L., Chen, X., \& Wan, Y. (2009). Desalination of Soy Sauce by Nanofiltration. Sep. Pur. Tech., 66, 429437. http://dx.doi.org/10.1016/j.seppur.2009.02.015

Luo, J., Huang, W., Song, W., Hang, X., Ding, L., \& Wan, Y. (2012). A Pilot-Plant Test on Desalination of Soy Sauce by Nanofiltration. Sep. Pur. Tech., 89, 217-224. http://dx.doi.org/10.1016/j.seppur.2012.01.026

Moraes, E. P., da Silva, N. S. A., de Morais, C. D. M., das Neves, L. S., \& de Lima, K. M. G. (2014). Low-Cost Method for Quantifying Sodium in Coconut Water and Seawater for the Undergraduate Analytical Chemistry Laboratory: Flame Test, a Mobile Phone Camera, and Image Processing. J. Chem. Educ., 91, 1958-1960. http://dx.doi.org/10.1021/ed400797k

Singh, D., Prashad, R., Parkash, C., Bansal, Y. S., Sharma, S. K., \& Pandey, A. N. (2002). Linearization of the relationship between serum sodium, potassium concentration, their ratio and time since death in Chandigarh zone of north-west India, Forensic Sci. Int., 130, 1-7. http://dx.doi.org/10.1016/S0379-0738(02)00267-0

Tian, H. G., Hu, G., Dong, Q. N., Yang, X. L., \& Nan, Y. (1996). Dietary Sodium and Potassium, Socioeconomic Status and Blood Pressure in a Chinese Population. Appetite, 26, 235-246. http://dx.doi.org/10.1006/appe.1996.0018

Vieira, E., Soares, M. E., Ferreira, I. M. P. L. V. O., \& Pinho, O. (2012). Validation of a Fast Sample Preparation Procedure for Quantification of Sodium in Bread by Flame Photometry. Food Anal. Methods, 5, 430-434. http://dx.doi.org/10.1007/s12161-011-9247-8

Yu, Y. H., Farmer, A., Mager, D., \& Willows, N. (2014). Dietary Sodium Intakes and Food Sources of Sodium in Canadian-Born and Asian-Born Individuals of Chinese Ethnicity at a Canadian University Campus. J. Amer. College Health, 62, 278-284. http://dx.doi.org/10.1080/07448481.2014.891594

\section{Copyrights}

Copyright for this article is retained by the author(s), with first publication rights granted to the journal.

This is an open-access article distributed under the terms and conditions of the Creative Commons Attribution license (http://creativecommons.org/licenses/by/3.0/). 